\title{
Diel and Circadian Patterns of Locomotor Activity in the Adults of Diamondback Moth (Plutella xylostella)
}

\author{
Danfeng Wang ${ }^{1,2,3,4}$, Guang Yang ${ }^{1,2,3,4, *}$ and Wenfeng Chen $5, *$ (D) \\ 1 State Key Laboratory of Ecological Pest Control for Fujian and Taiwan Crops, Institute of Applied Ecology, \\ Fujian Agriculture and Forestry University, Fuzhou 350002, China; adan10@foxmail.com \\ 2 Joint International Research Laboratory of Ecological Pest Control, Ministry of Education, College of Plant \\ Protection, Fujian Agriculture and Forestry University, Fuzhou 350002, China \\ 3 Key Laboratory of Integrated Pest Management for Fujian-Taiwan Crops, Ministry of Agriculture and Rural \\ Affairs, College of Plant Protection, Fujian Agriculture and Forestry University, Fuzhou 350002, China \\ 4 Ministerial and Provincial Joint Innovation Centre for Safety Production of Cross-Strait Crops, College of \\ Plant Protection, Fujian Agriculture and Forestry University, Fuzhou 350002, China \\ 5 Institute of Life Sciences, College of Biological Science and Engineering, Fuzhou University, \\ Fuzhou 350108, China \\ * Correspondence: yxg@fafu.edu.cn (G.Y.); chenwenfeng@fzu.edu.cn (W.C.)
}

Citation: Wang, D.; Yang, G.; Chen, W. Diel and Circadian Patterns of

Locomotor Activity in the Adults of Diamondback Moth (Plutella xylostella). Insects 2021, 12, 727. https://doi.org/10.3390/ insects12080727

Academic Editors: Giles E. Duffield and Brian T. Forschler

Received: 22 June 2021

Accepted: 12 August 2021

Published: 14 August 2021

Publisher's Note: MDPI stays neutral with regard to jurisdictional claims in published maps and institutional affiliations.

Copyright: (C) 2021 by the authors Licensee MDPI, Basel, Switzerland. This article is an open access article distributed under the terms and conditions of the Creative Commons Attribution (CC BY) license (https:// creativecommons.org/licenses/by/ $4.0 /)$.
Simple Summary: Plutella xylostell is a worldwide migratory insect pest that mainly damages cruciferous vegetables. In this study, we established a system for measuring the diel locomotor activities and used it to evaluate the locomotor circadian patterns of P. xylostella. We tested the locomotor activities of $P$. xylostella adults under several laboratory settings. We found that both the males and females showed nocturnal activity under a light:dark (LD) cycle, with activity peaking very early after lights off and quickly declining after lights on. Both males and females had high locomotor activity levels in constant darkness (DD) but weak in a constant light condition (LL). In addition, circadian patterns analysis showed that males exhibit much better rhythmic characteristics than females, especially in low temperature conditions. Overall, our proposed system for studying the locomotor activities in P. xylostella is reliable, which will help us to have a better understanding of the diel activity of $P$. xylostella and may finally be helpful in the development of an effective pest management strategy.

Abstract: The Diamondback Moth (Plutella xylostella) is a highly destructive lepidopteran pest of cruciferous crops. However, there still is relatively little known about the locomotor activities of diel and the circadian patterns in P. xylostella. Here, we present an analysis of the diel locomotion of $P$. xylostella under several laboratory settings. We established a system for measuring the individual locomotor activities of P. xylostella and found that both males and females showed a nocturnal pattern of activity under 26 or $20^{\circ} \mathrm{C}$ LD conditions, with activity peaking immediately after lights off and quickly declining after lights on. In addition, we showed that it is difficult to assess the free-running circadian rhythms of P. xylostella under $26^{\circ} \mathrm{C}$ DD conditions. However, we found that males showed a higher power, rhythm index $(R I)$ and rhythmic ratio than females under $20{ }^{\circ} \mathrm{C} \mathrm{DD}$ conditions, which indicated that males in low-temperature conditions are much more suitable to study the free-running circadian rhythms of $P$. xylostella. The findings of this study will help us to have a better understanding of the diel activity of $P$. xylostella and may provide a foundation for the development of an effective pest management strategy.

Keywords: Plutella xylostella; locomotor activity; circadian rhythm

\section{Introduction}

Circadian rhythms are found in most species as the earth rotates around its axis every twenty-four hours. The circadian clock controls daily rhythms in animal physiology 
and metabolism, thus playing important roles in organismal health and fitness. Insect behaviors, including locomotion, courtship, mating, sperm release, etc., are all affected by the circadian rhythm system [1,2]. Understanding the circadian rhythm of insects, especially lepidopteran pests, has an important reference value for formulating effective pest management strategies [3].

The circadian rhythms control various physiological activities of lepidopteran insects. The circadian rhythms of adult lepidopteran insects have specific characteristics, in which the butterfly species are active during the day, and many moths are active at night [4] The male gypsy moth (Lymantria dispar) exhibits a bimodal rhythm of locomotion and pheromone response, with one peak during the day and one peak at night [5]. This periodic change is affected by the endogenous circadian oscillator. Studies in Antherea pernyi, Hyalophora cecropia and Samia cynthia have shown that the biological clock controls the rhythm of emergence and migration [1]. The previous studies in Pectinophora gossypiella showed that the circadian clock controls the hatching time of eggs [6]. Egg hatching, adult emergence and adult activity showed prominent circadian rhythms in the Mediterranean meal moth (Ephestia kuehniella) [7]. In moths, pheromone-mediated reproductive behaviors at specific times have also been extensively studied. Female moths produce and release pheromones at specific times of the day, which is synchronized with the rhythm of male moths; those are sensitive to pheromones [8]. The phototransduction and circadian rhythm synchronization play a key role in the signal transduction mechanism of lepidopteran treetop disease caused by baculovirus [9].

The study in Drosophila melanogaster has laid an important foundation to understand the phenomenon of circadian rhythm and related mechanisms [2,10]. In Drosophila, the circadian rhythm of locomotor activity is usually measured by using the Drosophila Activity Monitoring (DAM) system (TriKinetics; Waltham, MA) [11]. Under light-dark (LD) conditions (usually alternating $12 \mathrm{~h}$ light and $12 \mathrm{~h}$ dark), flies exhibit a morning activity peak during dawn and an evening activity peak during dusk [2,10]. In constant darkness (DD), the morning peak gradually shrinks; only the evening peak persists and reflecting a circadian clock function with a near-24-hour period [2,10]. At the molecular level, a set of proteins (e.g., PERIOD, CLOCK, CRYPTOCHROME) function as transcription-based feedback loops or post-translational regulation within the clock $[2,10]$. At the level of the cells, a circadian pacemaker neural network mediates distinct aspects of locomotor behavior $[2,10]$.

However, studies on the biological clock of other insects have shown that there may be some differences from Drosophila [12]. The differences in the circadian clock genes in insects stress the complexity in the evolution of clock genes in different insects [13]. $P$. xylostella is a worldwide migratory insect pest that mainly damages cruciferous vegetables and causes economic loss up to USD $4-5$ billion annually [14,15]. Here, we explore the locomotor activity rhythms of P. xylostella in the laboratory using the DAM system. The main objective of this study is to assess the diel locomotor activities in P. xylostella adults. We developed a modified system that can stably monitor the locomotor activities of adult $P$. xylostella. In addition, we discovered robust rhythmic behavior in males but weak rhythmic in females under DD conditions.

\section{Materials and Methods}

\subsection{Insect Sample}

P. xylostella Geneva 88, an insecticide-susceptible strain, was provided by Professor Shelton from Cornell University in 2016 and kept in Fujian Agriculture and Forestry University under $25 \pm 1{ }^{\circ} \mathrm{C}, 70-80 \%$ relative humidity and 14L:10D (14 h light:10 h dark) photoperiod. The larvae were reared in a paper cup $(10.4 \mathrm{~cm} \times 7.3 \mathrm{~cm} \times 8.5 \mathrm{~cm})$ with an artificial diet. The pupae were transferred to a new paper cup for eclosion. Newly emerged G88 adults were fed with $10 \%$ honey water to supplement their nutrition. 


\subsection{Activity Monitor System}

A basic system contains the following components: data collection computer, PSIU9 power supply interface unit, activity monitors, tubes and caps and incubator to provide temperature/light stability. Locomotor activity monitors (model number LAM16) and the PSIU9 power supply interface unit were obtained from Trikinetics Inc. (Waltham, MA, USA). Each LAM16 monitor unit has 32 independent channels (16 mm diameter), which were used to load the adults of P. xylostella in sampling tubes and to measure locomotor activity using infrared beams and sensors. The sample tubes were made of Polymeric Methyl Methacrylate (PMMA) with a 12-millimeter inside diameter $\times 100 \mathrm{~mm}$ length. Usually, the length of $P$. xylostella adults is about $6 \mathrm{~mm}$. After being occupied by food and stopper, there is about $50 \mathrm{~mm}$ length of free space left. After eclosion, the three days old P. xylostella were anesthetized with $\mathrm{CO}_{2}$ and loaded into the sample tubes at Zeitgeber time 10 (ZT10). Both sexes were kept in the same incubator, and they were able to smell the pheromones of the others. Incubators with a white LED (light-emitting diode) light source were used (light intensity is about 500 lux). LAM16 monitors were connected to the computer with PSIU9 Power Supply Interface Unit. The DAMSystem3 (Waltham, MA, USA) data collection program was set to collect 1-minute bins data from each activity monitor and saved the data in the respective raw monitor file on the hard drive. Then, the FileScan (Waltham, MA, USA) program was used to scan and produce 1-minute bins and 30-minute bins channel files. These files are then ready for analysis.

\subsection{Locomotor Activity Behaviors Analysis}

Rhythmic data can be considered as a wave, and the analysis of locomotor activity data is mainly concerned with a period (the time for a rhythmic event to repeat itself) and amplitude (the robustness of the endogenous clock) [16]. Here, locomotor activities were analyzed using the MATLAB toolboxes developed in Jeffrey Hall's laboratory [17] and the FaasX developed in François Rouyer's laboratory [18]. The output of MATLAB toolboxes provides data on the individual's locomotor activities throughout the experiment in the form of an actogram, an autocorrelation, which calculates the strength of their rhythms using circular statistics [17]. Double-plotted actograms were used to highlight the locomotor activity patterns at different days. Mean activity plots were used to show the activity patterns of $24 \mathrm{~h}$. Autocorrelation plots were used to determine the rhythm index $(R I)$, as described previously [17]. Briefly, the oscillation of this autocorrelation function shows periodicity. The asterisk above the third peak of the autocorrelation graph indicates the specific time point used to assess the RI [17]. Phase under LD conditions was determined with the FaasX software. Briefly, individuals' survival at least through the data range requested was used. Data with high frequencies were filtered and the peak was selected as the phase point. Chi square periodogram analysis in FaasX was performed to determine the rhythmicity under DD conditions. Briefly, to justify rhythmicity, Chi-square significance level was set to 0.05 , and minimum period peak power and minimum period peak width were set to 20 and $1.5 \mathrm{~h}$, respectively. The parament of power derived from Chi square periodogram analysis reflects the robustness of the endogenous rhythm.

\section{Results}

\subsection{System for Measuring the Individual Locomotor Activities of P. xylostella}

The locomotor activity monitors were developed by Trikinetics Inc. (Waltham, MA, USA) and used to quantify animal movement over time [19]. Here, we used model number LAM16 to monitor the circadian rhythm of $P$. xylostella, which has previously been used to measure individual locomotor rhythms in honey bees or mosquitoes [20-22] (Figure 1a). In this study, individuals of $P$. xylostella were placed into the tubes with a supply of food, which contains an infrared beam. The computer recorded the locomotor activity as the individuals move back and forth to break the beam. A single activity monitor consists of 32 independent channels, which measure activity using three pairs of infrared emitters and sensors positioned alongside the tubes. The associated electronic components convert 
analogue information into binary data. One of the main challenges in using the Trikinetics system in P. xylostella is the supply of food. We designed a food system that can provide honey food for several days. The food system was built from the head of a 3-milliliter Pasteur pipette, filter paper, cotton, sampling tube, gummed tape and honey (Figure 1a). Firstly, the 2.5-milliliter honey was diluted twice by sterile water, packed into the head of the 3-milliliter Pasteur pipette and 2-3 pieces of suitable size filter paper were put into the diluted honey (Figure 1b). Secondly, the head of the 3-milliliter Pasteur pipette with the honey and filter paper was assembled into one side of the sampling tube and stuffed with a cotton ball to absorb the honey (Figure 1b). Then, the connection between the head of the 3-milliliter Pasteur pipette and the sampling tube was fixed with gummed tape (Figure 1b). Finally, the P. xylostella adults were placed in the sampling tube, a stopper was added at the other end of the tubes and then assembled on the LAM16 monitor (Figure 1b).

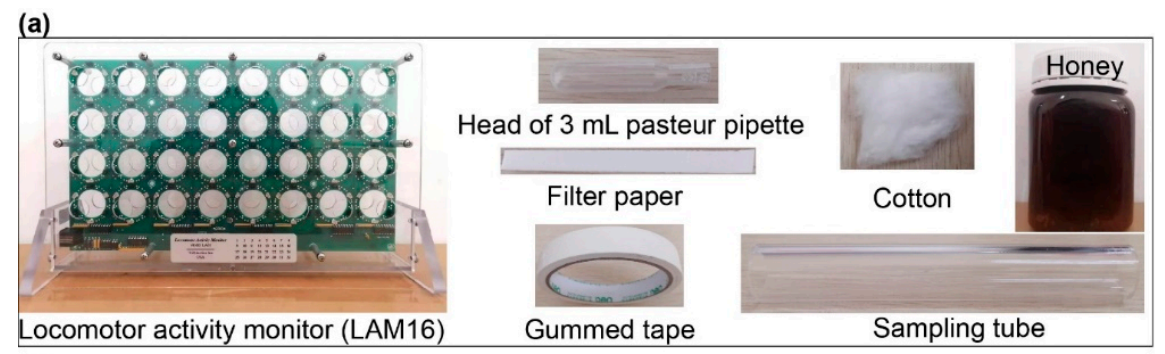

(b)

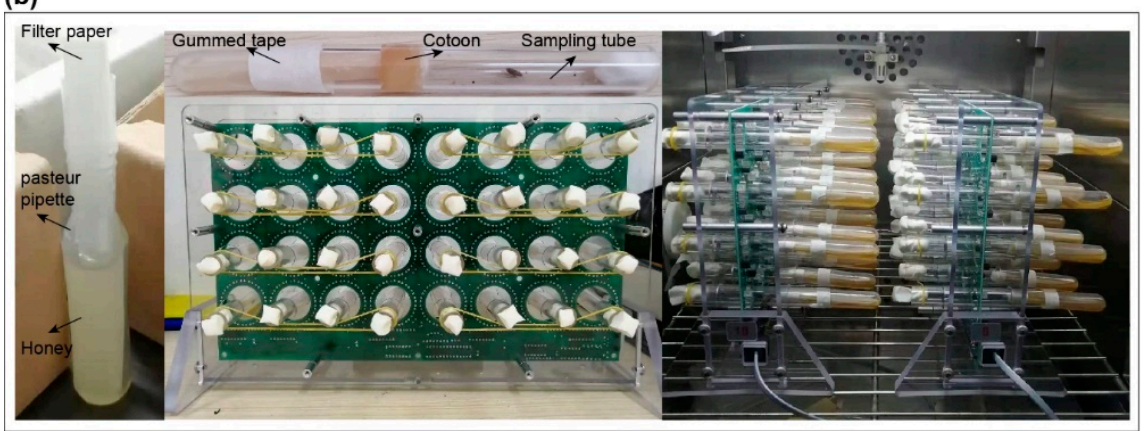

Figure 1. Locomotor activity monitoring system for P. xylostella. (a) Description of what is contained in the panel (b); (b) System assembly ensures that every P. xylostella individual has a constant supply of honey solution. Fully assembled LAM system, including the food system assembly and the sampling tubes.

\subsection{Locomotor Activities of P. xylostella under Different Temperatures}

To test whether the conditions of our activity monitoring system can work well on $P$. xylostella, we started by analyzing the locomotor activities of the male and female moths under standard laboratory conditions. The locomotor activities of the single female and male moth were assessed under $26^{\circ} \mathrm{C}$ and 14L:10D conditions for four days, followed by DD for five to six days. Consistent with previous reports that the P. xylostella adults are usually active at twilight and throughout the night [23], we found a nocturnal pattern of activity under LD, with peaking immediately after lights off and quickly declining after lights on (Figure 2a). The autocorrelation analysis of the circadian locomotor activities under LD revealed that both the female and male moth had a period of nearly $24 \mathrm{~h}$ (male $24.03 \pm 0.16 \mathrm{~h}$, female $24.07 \pm 0.16 \mathrm{~h}$ ), and both had an average rhythm index (RI) of about 0.3 (male $0.28 \pm 0.02$, female $0.26 \pm 0.02$ ) (Figure $2 \mathrm{a}$ and Table 1 ). The peak phase or average activity analysis was comparable in the males and females (Tables 1 and 2). In DD conditions, we found that both the male and female moths had high locomotor activity levels, either in the subjective day or night (Figure 2b). However, the analysis of the locomotor activity rhythms under DD revealed that they were highly arrhythmic (male arrhythmic $=21 / 29$ vs. female arrhythmic $=33 / 35$ ). Autocorrelation analysis showed that both the female and male moth had very weak oscillation in the period, and the average RIs 
of the males and females were only $0.15 \pm 0.01$ and $0.12 \pm 0.02$, respectively (Figure $2 b$ and Table 1). Although the Chi square periodogram analysis of rhythmic individuals showed that the males have higher power than the females under the DD condition (Table 1), all of these data indicate that it is difficult to assess the free-running circadian rhythms of $P$. xylostella under the $26^{\circ} \mathrm{C}$ condition.
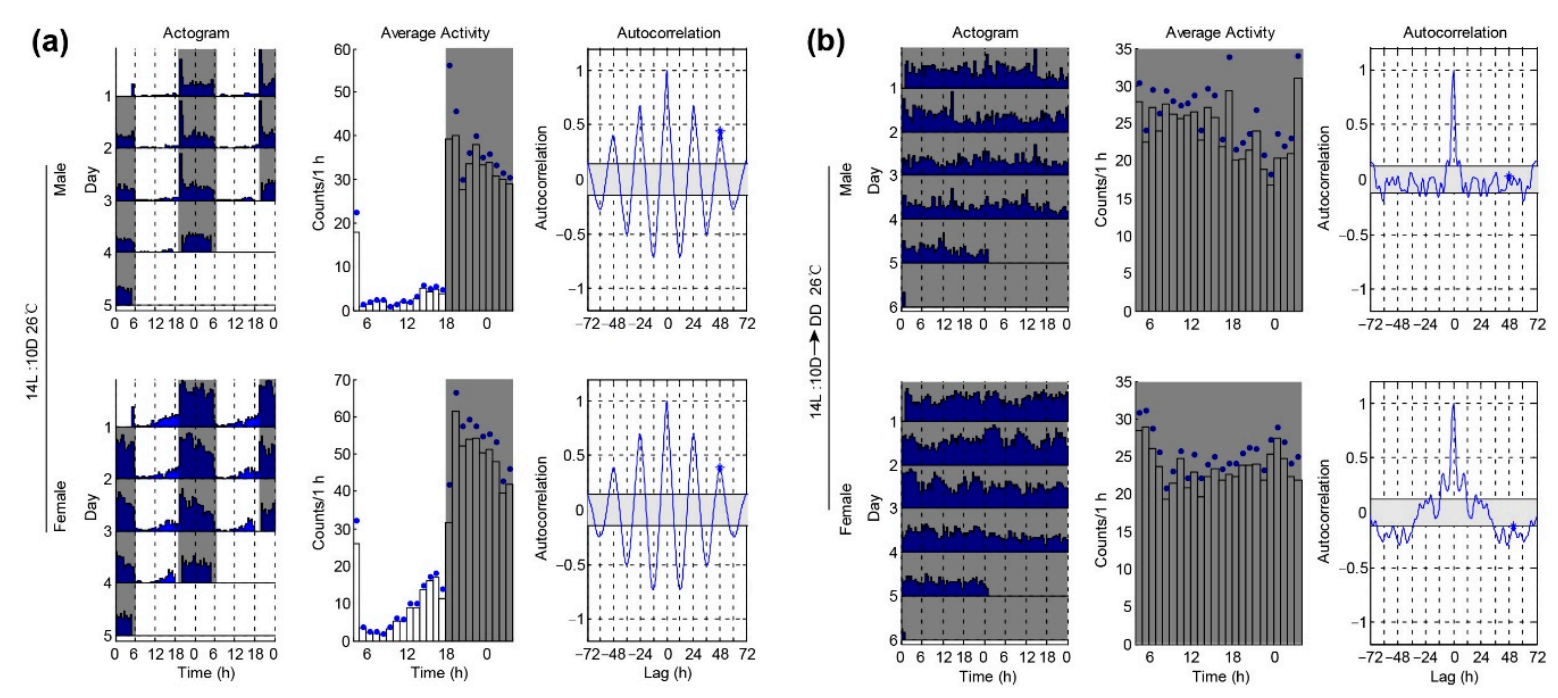

Figure 2. Locomotor activity rhythms of P. xylostella male and female at $26^{\circ} \mathrm{C}$. (a) Locomotor activity rhythms of $P$. xylostella under the 14L:10D condition. Double-plotted actograms show the locomotor activity patterns of the different days (the left panel). Each row contains two consecutive days of locomotor activities (counts per $30 \mathrm{~min}$ ), and the last day is repeated to ensure that the next day is always the beginning of the next row. The x-axis shows the day under the light-dark condition. Average activity plots show the activity patterns (the middle panel). The blue dots on the plots are SEM. The gray shadings in the plot denote the light-off condition. Autocorrelation plots are used to determine the rhythm index (RI) (right panel). (b) Locomotor rhythms of P. xylostella under constant darkness.

Table 1. Locomotor activity circadian rhythms of P. xylostella under different light conditions.

\begin{tabular}{|c|c|c|c|c|c|c|c|c|}
\hline \multirow[t]{3}{*}{ Condition } & \multicolumn{2}{|c|}{$\begin{array}{c}\text { Phase }(95 \% \text { Confidence } \\
\text { Limit) }\end{array}$} & Power & $\begin{array}{c}\text { Average } \\
\text { Rhythm Index } \\
\text { (RI) }\end{array}$ & \multicolumn{2}{|c|}{$\begin{array}{c}\text { Phase }(95 \% \text { Confidence } \\
\text { Limit) }\end{array}$} & Power & $\begin{array}{l}\text { Average } \\
\text { Rhythm } \\
\text { Index (RI) }\end{array}$ \\
\hline & \multicolumn{4}{|c|}{ Male } & \multicolumn{4}{|c|}{ Female } \\
\hline & \multicolumn{8}{|c|}{ LD (4 days) } \\
\hline $\begin{array}{l}26^{\circ} \mathrm{C} \text { 14L:10D } \\
20^{\circ} \mathrm{C} \text { 14L:10D } \\
20^{\circ} \mathrm{C} \text { 10L:14D }\end{array}$ & \multicolumn{2}{|c|}{$\begin{array}{c}2.0 \pm 0.6 \\
22.5 \pm 0.9\end{array}$} & $\begin{array}{c}54.2 \pm 3.07^{\text {n.s. }} \\
70.9 \pm 3.98^{* *} \\
55.9 \pm 2.87^{*}\end{array}$ & $\begin{array}{c}0.28 \pm 0.02^{\text {n.s. }} \\
0.31 \pm 0.02^{* *} \\
0.29 \pm 0.02^{* *}\end{array}$ & $\begin{array}{r}2.8 \pm \\
2.4 \pm \\
22.0=\end{array}$ & $\begin{array}{c}2.4 \pm 1.1 \\
22.0 \pm 0.3\end{array}$ & $\begin{array}{l}50.4 \pm 3.07 \\
54.5 \pm 3.36 \\
50.4 \pm 3.81\end{array}$ & $\begin{array}{l}0.26 \pm 0.02 \\
0.23 \pm 0.02 \\
0.16 \pm 0.04\end{array}$ \\
\hline \multirow[t]{2}{*}{ Condition } & $\begin{array}{l}\text { Arrhythmic } \\
\text { Ratio }\end{array}$ & Period & Power & $\begin{array}{c}\text { Average } \\
\text { Rhythm Index } \\
\text { (RI) }\end{array}$ & $\begin{array}{l}\text { Arrhythmic } \\
\text { Ratio }\end{array}$ & Period & Power & $\begin{array}{l}\text { Average } \\
\text { Rhythm } \\
\text { Index (RI) }\end{array}$ \\
\hline & \multicolumn{8}{|c|}{ LD-DD or LD-LL (5-6 days) } \\
\hline $\begin{array}{c}26^{\circ} \mathrm{C} \\
14 \mathrm{~L}: 10 \mathrm{D}-\mathrm{DD}\end{array}$ & $21 / 29 *$ & $24.3 \pm 2.85$ & $41.3 \pm 6.07^{*}$ & $0.15 \pm 0.01^{\text {n.s. }}$ & $33 / 35$ & $25.8 \pm 1.25$ & $25.7 \pm 2.58$ & $0.12 \pm 0.02$ \\
\hline $\begin{array}{c}20^{\circ} \mathrm{C} \\
14 \mathrm{~L}: 10 \mathrm{D}-\mathrm{DD}\end{array}$ & $20 / 38^{* * *}$ & $24.0 \pm 0.31$ & $46.4 \pm 3.80^{* *}$ & $0.19 \pm 0.01 * *$ & $36 / 41$ & $27.0 \pm 1.81$ & $37.6 \pm 3.47$ & $0.14 \pm 0.02$ \\
\hline $\begin{array}{c}20^{\circ} \mathrm{C} \\
\text { 10L:14D-DD }\end{array}$ & $10 / 21 * * *$ & $23.8 \pm 0.28$ & $36.6 \pm 6.35$ & $0.16 \pm 0.02^{* *}$ & $20 / 20$ & - & - & $0.10 \pm 0.03$ \\
\hline $\begin{array}{c}20^{\circ} \mathrm{C} \\
14 \mathrm{~L}: 10 \mathrm{D}-\mathrm{LL}\end{array}$ & $20 / 20$ & - & - & - & $16 / 16$ & - & - & - \\
\hline
\end{tabular}

Note: Period, power and arrhythmic ratio were calculated using Chi-square periodogram analysis. Individual survival at least through the data range requested were used to perform analysis, and only the rhythmic individuals were used to calculate period and power. Rhythm index was calculated using autocorrelation analysis (all survival individuals were used). Comparisons were made between males and females with a two-tailed, unpaired Student's $t$-test. ${ }^{*} p<0.05,{ }^{* *} p<0.01,{ }^{* * *} p<0.001$, n.s. no significance. 
Table 2. Daily activity levels of $P$. xylostella under different light conditions.

\begin{tabular}{|c|c|c|c|c|}
\hline Condition & Number & Activity: Average/30 min & Number & Activity: Average $/ 30 \mathrm{~min}$ \\
\hline & & Male & & emale \\
\hline & \multicolumn{4}{|c|}{ LD (4 days) } \\
\hline $26^{\circ} \mathrm{C} 14 \mathrm{~L}: 10 \mathrm{D}$ & 42 & $31.5 \pm 4.05$ & 46 & $30.4 \pm 2.94$ \\
\hline $20{ }^{\circ} \mathrm{C} 14 \mathrm{~L}: 10 \mathrm{D}$ & 40 & $35.8 \pm 3.22$ & 42 & $31.7 \pm 3.62$ \\
\hline $20^{\circ} \mathrm{C} 10 \mathrm{~L}: 14 \mathrm{D}$ & 30 & $46.5 \pm 4.55$ & 28 & $26.7 \pm 2.81$ \\
\hline \multirow[t]{2}{*}{ Condition } & Number & Activity: Average/30 min & Number & Activity: Average/30 min \\
\hline & \multicolumn{4}{|c|}{ DD (4 days) or LL (4 days) } \\
\hline $26^{\circ} \mathrm{C} 14 \mathrm{~L}: 10 \mathrm{D}-\mathrm{DD}$ & 29 & $23.9 \pm 3.11$ & 35 & $26.0 \pm 3.00$ \\
\hline $20^{\circ} \mathrm{C} 14 \mathrm{~L}: 10 \mathrm{D}-\mathrm{DD}$ & 38 & $20.3 \pm 3.07$ & 41 & $15.6 \pm 2.31$ \\
\hline $20^{\circ} \mathrm{C}$ 10L:14D-DD & 21 & $24.7 \pm 2.85$ & 20 & $19.3 \pm 2.53$ \\
\hline $20^{\circ} \mathrm{C} 14 \mathrm{~L}: 10 \mathrm{D}-\mathrm{LL}$ & 20 & $6.1 \pm 1.44$ & 16 & $8.2 \pm 1.53$ \\
\hline
\end{tabular}

We then decided to test whether temperature compensation is involved in affecting the locomotor rhythm under DD. Temperature compensation enables organisms to maintain robust rhythms with a period close to a day over a wide range of physiological temperatures. We set the locomotor activities of single females and males P. xylostella under $20^{\circ} \mathrm{C}$ and 14L:10D conditions. Similar to the results of $26^{\circ} \mathrm{C}$, we still found that both the male and female moths showed a nocturnal pattern of locomotion under LD and had similar phases (male, $2.0 \pm 0.6 \mathrm{~h}$; female, $2.4 \pm 1.1 \mathrm{~h}$ ) (Figure 3a and Table 1). Furthermore, we found that the average activity levels of the males and females were similar (Figure $3 \mathrm{~b}$ and Table 2). The arrhythmic ratio of the females was significantly higher than that of the males under $20^{\circ} \mathrm{C}$ and DD conditions (male arrhythmic $=20 / 38$ vs. female arrhythmic $\left.=36 / 41\right)($ Table 1$)$. The average power and RI of the males under DD were also significantly higher than the females (Figure $3 \mathrm{~b}$ and Table 1). These results indicated that the males had a better rhythm than the females under a low temperature. This finding is surprising because the ability to maintain a fixed endogenous period throughout a range of physiological temperatures (temperature compensation) is a defining feature of circadian rhythms. Subsequently, we carried out the experiments under $20^{\circ} \mathrm{C}$.

\subsection{Locomotor Activities of P. xylostella under a Winter-like Short Day}

Light is the dominant environmental cue that provides temporal information to circadian pacemakers. Here, we wondered whether the photoperiod affects the locomotor rhythm of P. xylostella. In the former 14L:10D condition, we provided a summer-like long day. Next, we set a winter-like short day condition with 10L:14D. We found that both the male and female moths still showed nocturnal patterns under 10L:14D and had comparable peak phases (Figure 4a and Table 1). Similar to the results under 14L:10D, the females still showed a higher arrhythmic ratio than the males when transferred from 10L:14D to DD (male arrhythmic $=10 / 21$ vs. female arrhythmic $=20 / 20)($ Figure $4 \mathrm{~b}$ and Table 1$)$. The average power and RI of the males under DD were also significantly higher than the females (Figure $4 \mathrm{~b}$ and Table 1). Together, these data show that P. xylostella under a winter-like short day had a similar locomotor rhythm as the moths under a summer-like long day (Figures 3 and 4). 

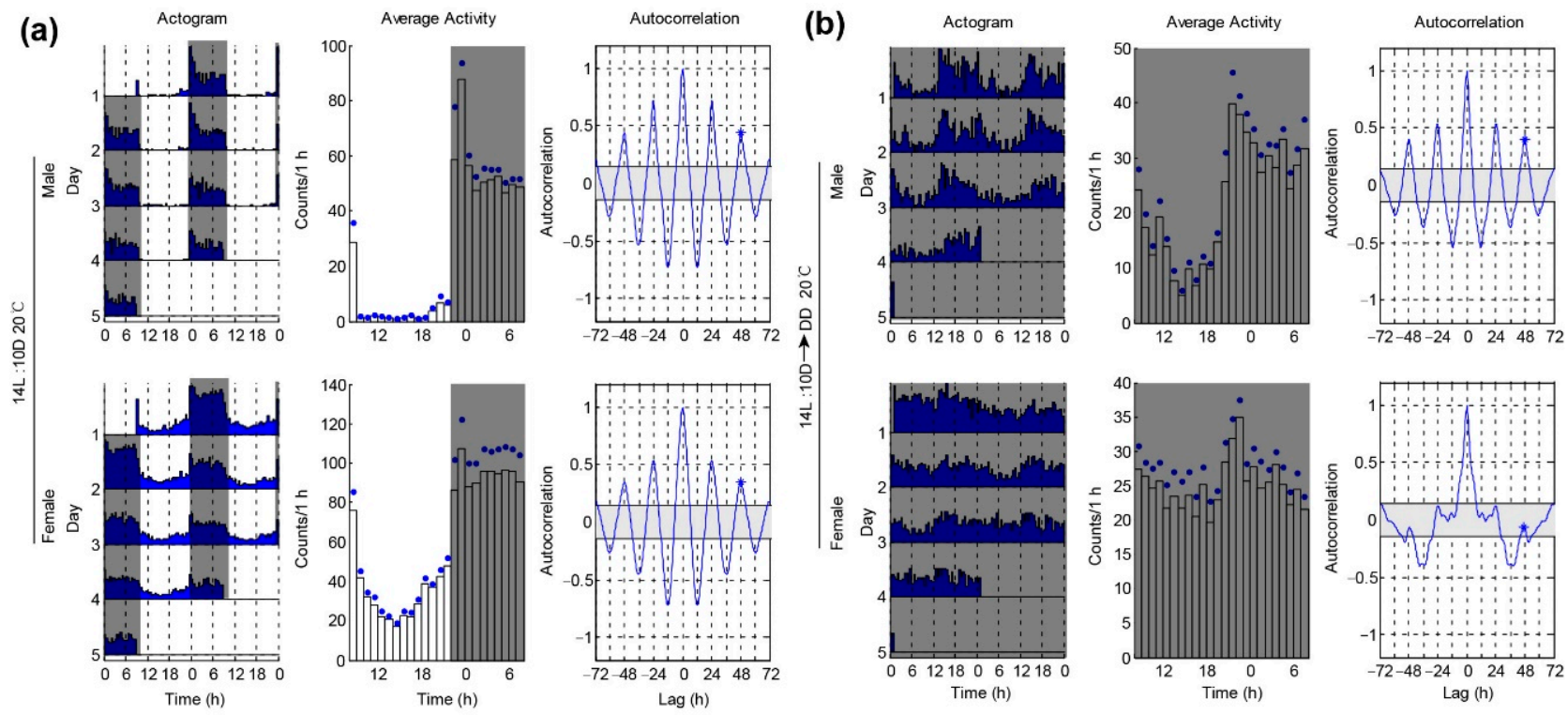

Figure 3. P. xylostella males exhibit better rhythm than females under $20^{\circ} \mathrm{C}$. (a) Locomotor activity rhythms of $P$. xylostella under 14L: 10D and $20^{\circ} \mathrm{C}$ conditions. Double-plotted actograms show the locomotor activity patterns of the different days (left panel). Each row contains two consecutive days of locomotor activities (counts per $30 \mathrm{~min}$ ), and the last day is repeated to ensure that the next day is always the beginning of the next row. The x-axis shows the time of day under LD conditions. Mean activity plots were used to show the activity patterns (middle panel). The blue dots on the plots are SEM. The gray shadings in the plots denote light-off conditions. Autocorrelation plots are used to determine the rhythm index (RI) (right panel). (b) Locomotor activity rhythms of the P. xylostella under the changing condition from 14L:10D to DD at $20^{\circ} \mathrm{C}$.

(a)

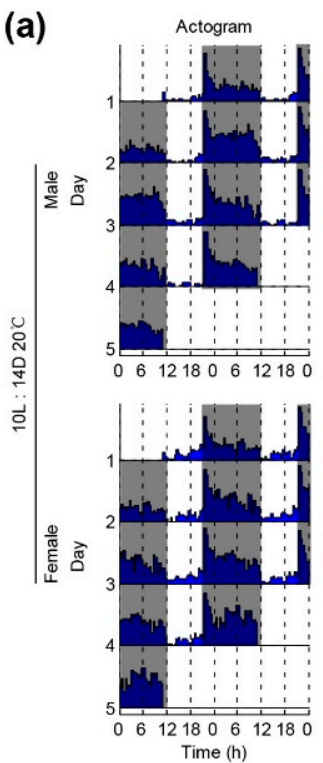

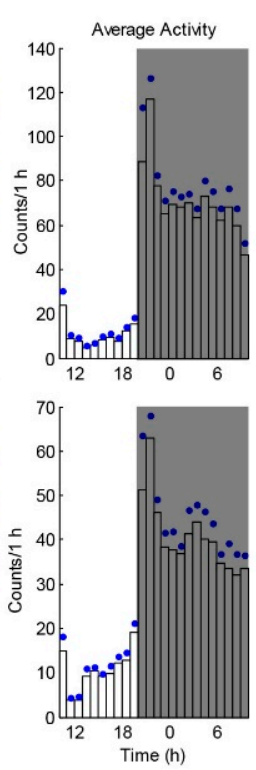

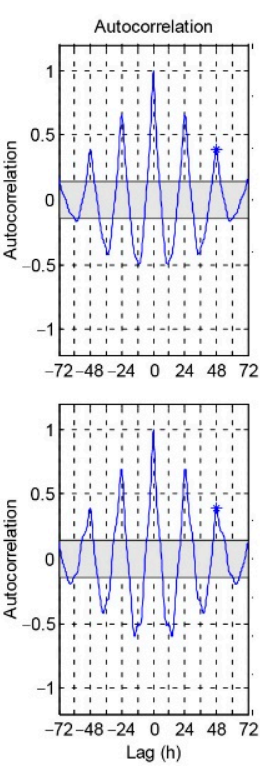

(b)

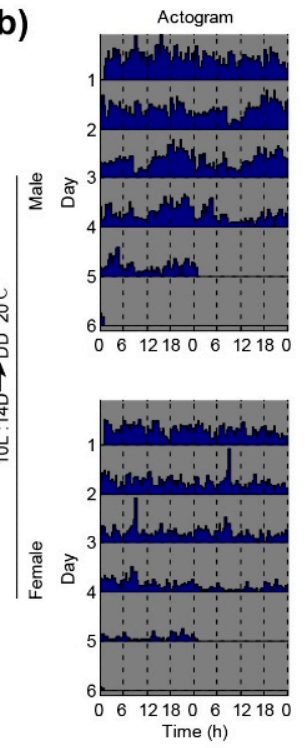

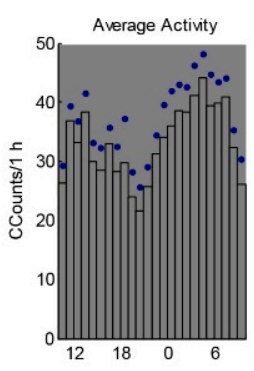
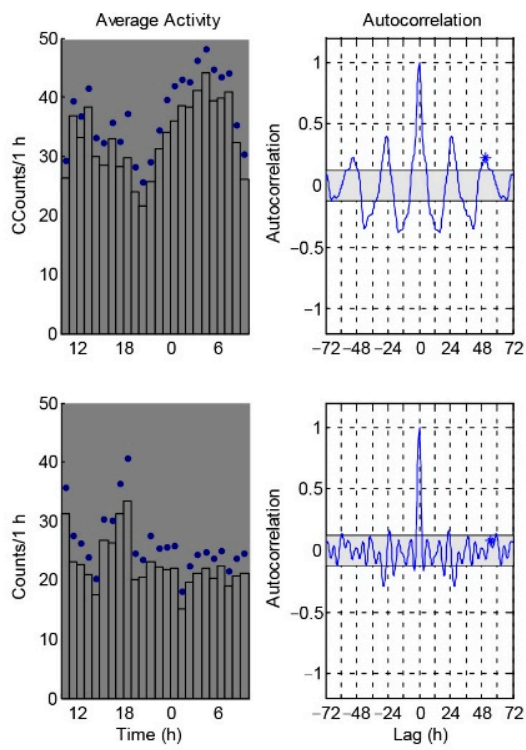

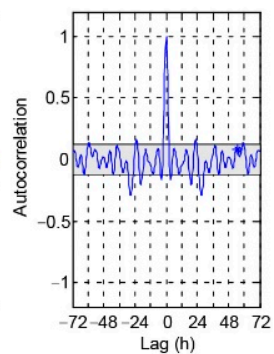

Figure 4. P. xylostella males show better rhythm than females under a winter-like short day at $20{ }^{\circ} \mathrm{C}$. (a) Locomotor rhythm of P. xylostella under 10L:14D and $20^{\circ} \mathrm{C}$ conditions. Double-plotted actograms show the locomotor activity patterns of the different days (left panel). Each row contains two consecutive days of locomotor activities (counts per $30 \mathrm{~min}$ ), and the last day is repeated to ensure that the next day is always the beginning of the next row. The x-axis shows the time of day under LD conditions. Mean activity plots are used to show the activity patterns (middle panel). The blue dots on the plots are SEM. The gray shadings in the plots denote light-off conditions. Autocorrelation plots are used to determine the rhythm index $(R I)$ (right panel). (b) Locomotor activity rhythms of P. xylostella under the changing condition from 10L:14D condition to DD at $20^{\circ} \mathrm{C}$. 


\subsection{Locomotor Activities of P. xylostella under Constant Light Condition}

In Drosophila melanogaster, constant light (LL) conditions stop the molecular cycling and cause wild-type flies to become arrhythmic [24]. To test whether the P. xylostella has a rhythm activity pattern under the LL condition, we kept the P. xylostella individuals under LD condition for four days and then transferred them to LL. Both the male and female moths showed the normal nocturnal activity pattern during LD (Figure 5a). However, in contrast to the males with normal rhythm under DD conditions, we found that both the males and females showed arrhythmic activity in LL with only about 6-8 counts of activity events every $1 \mathrm{~h}$ (Figure $5 \mathrm{~b}$ and Tables 1 and 2). These data indicate that light is an important factor in inhibiting the locomotor activities of $P$. xylostella.
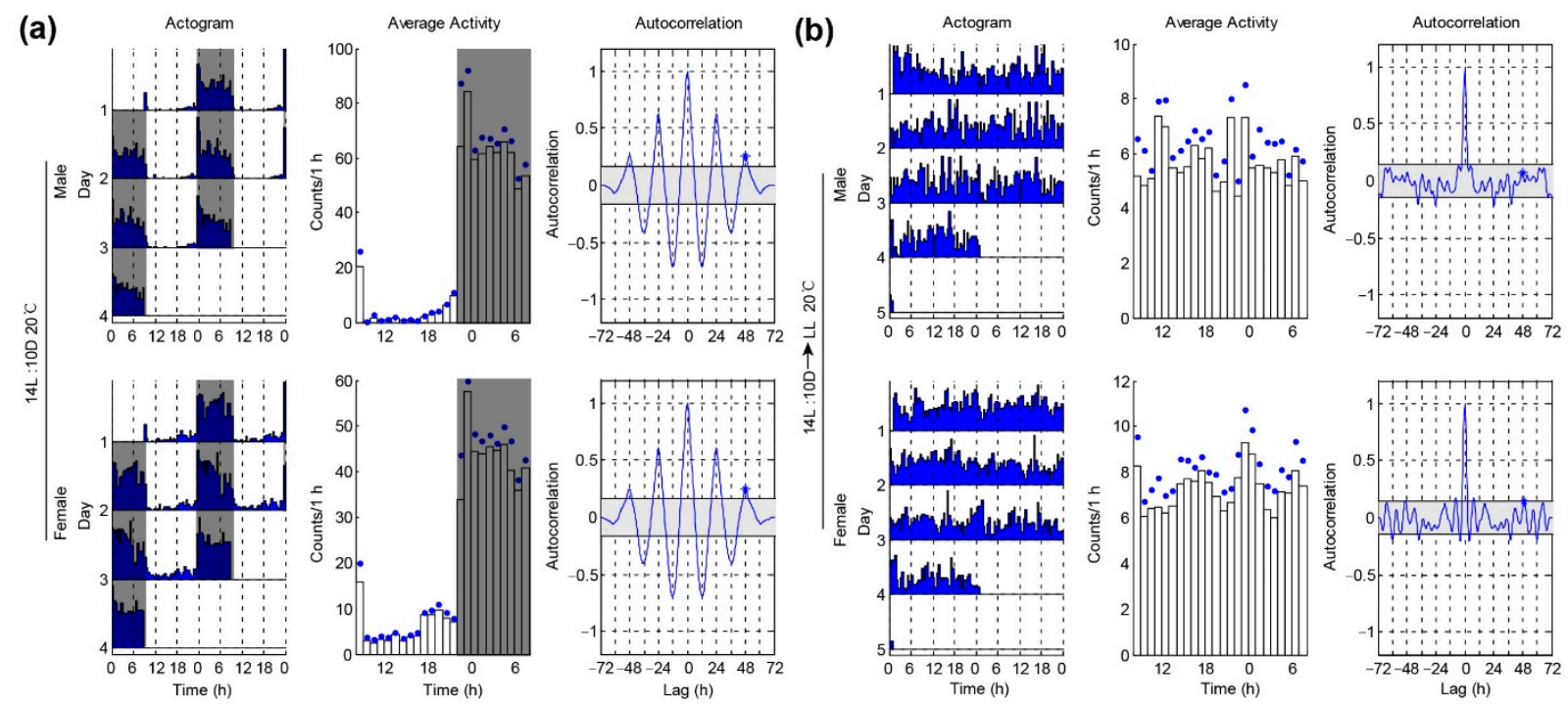

Figure 5. Both P. xylostella males and females exhibit arrhythmic when transferred from 14L:10D condition to LL. (a) Locomotor rhythm of P. xylostella under 14L:10D condition. Double-plotted actograms show the locomotor activity patterns of the different days (left panel). Each row contains two consecutive days of locomotor activities (counts per $30 \mathrm{~min}$ ), and the last day is repeated to ensure that the next day is always the beginning of the next row. The x-axis shows the time of day under light-dark conditions. Average activity plots used to show the activity patterns (middle panel). The blue dots on the plots are SEM. The gray shadings in the plots denote light-off conditions. Autocorrelation plots are used to determine the rhythm index (RI) (right panel). (b) Locomotor rhythms of P. xylostella under the changing condition from 14L:10D condition to constant light.

\section{Discussion}

Most insects show unimodal activity patterns [25]. However, small insect species with crepuscular habits are bimodal. The most important species with these aspects are Drosophila and mosquitoes. Many Drosophila species show a bimodal activity rhythm with peaks close to dawn and dusk, and a suppression of activity around noon $[2,10]$. Drosophila gradually increases their locomotor activity in advance of both dark-to-light and light-to-dark transitions, a phenomenon termed anticipation [2,10]. Interestingly, our data show that $P$. xylostella also appears to increase their activity gradually before switching from light to dark (see the average activity plots under LD conditions). Most of the moths show unimodal activity patterns may peak at different times. Here, we found the rhythm of the male and female locomotor activity reaching the peak at dusk in $P$. xylostella, whether under the long-day (14L:10D) or the short-day (10L:14D) conditions. Similar to our results, circadian locomotor activity in the adult fall armyworm, Spodoptera frugiperda, shows activity during darkness, with activity immediately after lights-off [26]. Both the Indian meal moth, Plodia interpunctella and the Mediterranean flour moth, Ephestia kuehniella show daily rhythms in calling and locomotor behaviors [27]. The rhythm of male locomotor activity reaches the peak at dusk in P. interpunctella and dawn in E. kuehniella [27]. 
However, under long-day conditions (17L:7D), both P. interpunctella and E. kuehniella tend to display bimodal activity patterns [28]. Whether P. xylostella will also show bimodal pattern under longer daytime is worthy of being studied further. Interestingly, the rhythms of calling behavior turn arrhythmic in P. interpunctella females in DD, whereas E. kuehniella females showed a persistent rhythm in DD, suggesting a different circadian clock regulation mechanism of moths [27]. On the other hand, a lot of the general activity level of P. xylostella can be explained by just the absence/presence of light. The activity, at least in the females, seems to be a direct light response (inhibition of locomotor activity) rather than a circadiandriven behavior. In the future, we may be able to study this question by making mutants of different clock genes.

It has been reported that different behaviors in insects are affected by temperature change. The circadian rhythm of locomotor activity under DD has been observed in many insect species and is now regarded as a property of the endogenous system [29]. However, we found that both P. xylostella males and females showed highly arrhythmic free-running behavior under $26{ }^{\circ} \mathrm{C}$. In contrast, males show better locomotor rhythm under $20{ }^{\circ} \mathrm{C}$. Circadian clocks are synchronized with both light:dark cycles and temperature fluctuations. Temperature changes may affect the clock mechanism by changing the component process, as seen in Drosophila and other insects. The Drosophila clock genes can be entrained by temperature cycles [28]. Antennal temperature signals regulated by the TRPA channel PYREXIA synchronize clock neurons in the brain to regulate the Drosophila circadian clock protein PERIOD [30]. Similar to locomotor rhythm, it has been reported that the adult emergence rhythm can also be affected by different temperature cycles [31]. The peaks of emergence in P. xylostella were delayed with the increase in temperature [32]. Temperature affects the sexual activity of moths generally, such that at lower temperatures females call earlier, and that a decrease in temperature may lift the inhibition of calling instead of inducing calling [8]. Temperature can also play a critical role in the circadian system to control sperm release in moths [33]. Measuring the locomotor rhythm of the honey bee at different temperatures reveals that testing the endogenous rhythm at $35{ }^{\circ} \mathrm{C}$ results in periods closer to $24 \mathrm{~h}$ compared with $25^{\circ} \mathrm{C}$ [20]. These findings suggest that the degree of tuning of circadian temperature compensation may vary among different species.

According to 'Aschoff's rule', $\tau$ lengthens with an increase in light intensity, or on transfer from DD to LL, for dark-active animals (i.e., $\tau \mathrm{DD}<\tau \mathrm{LL}$, nocturnal), but shortens for light-active animals (i.e., $\tau \mathrm{DD}>\tau \mathrm{LL}$, diurnal) [34]. However, the general applicability of this 'rule' in insects is in doubt. In some nocturnal species, the results for a transfer from DD to LL, and vice versa, are generally in agreement with 'Aschoff s rule'. Locomotor and flight activity rhythms frequently become arrhythmic in LL at higher light intensities. Here, we also found that P. xylostella became arrhythmic in LL. However, whether light intensity affects the rhythm of $P$. xylostella under LL needs to be studied further.

Understanding the biological clocks of insects could help us to develop more effective pest control strategies. The circadian rhythms of certain insects make them more susceptible to insecticides at certain times of the day than at other times [35], because the susceptibility to insecticide can be influenced by the rhythmic activity of xenobiotic metabolizing (XM) enzymes. For example, the enzymatic assay of glutathione S-transferase (GST), esterase and P450 in Cimex lectularius reveal significant time-of-day specific changes that have similar peak phases with the highest activity consistently recorded during the late photophase at ZT9 in LD [36]. The XM gene expression assays also reveal significant time-of-day differences in mRNA expression patterns in both LD and DD. Here, for the first time, we systematically studied the locomotor circadian rhythm of the P. xylostella. We believe that our results will be helpful in the future to clarify the molecular mechanism of the circadian rhythm of the P. xylostella and finally be helpful in the development of an effective pest management strategy. 


\section{Conclusions}

A system for measuring the individual locomotor rhythm of P. xylostella is established. Both the males and females show a nocturnal pattern of activity, with activity peaking very early after lights off and quickly declining after lights on. It is difficult to assess the free-running circadian rhythms of $P$. xylostella under $26^{\circ} \mathrm{C}$ DD conditions. Males in low-temperature conditions are much more suitable to study the free-running circadian rhythms of P. xylostella.

Author Contributions: Conceptualization, W.C. and G.Y.; methodology, W.C.; software, D.W. and W.C.; validation, D.W. and W.C.; formal analysis, D.W. and W.C.; investigation, D.W. and W.C.; resources, W.C. and G.Y.; data curation, W.C. and G.Y.; writing-original draft preparation, D.W. and W.C.; writing—review and editing, W.C. and G.Y.; visualization, W.C.; supervision, W.C. and G.Y.; project administration, W.C.; funding acquisition, W.C. and G.Y. All authors have read and agreed to the published version of the manuscript.

Funding: This research was funded by the National Natural Science Foundation of China (grant number 31970461, 31772237), the Fujian Natural Science Foundation (grant number 2020J02027).

Institutional Review Board Statement: Not applicable.

Data Availability Statement: All data is available in this paper.

Acknowledgments: We thank Muhammad Asad for critical comments on the manuscript. We would also like to thank Arlene Haney for language improvements on the manuscript.

Conflicts of Interest: The authors declare no conflict of interest.

\section{References}

1. Numata, H.; Miyazaki, Y.; Ikeno, T. Common features in diverse insect clocks. Zool. Lett. 2015, 1, 10. [CrossRef] [PubMed]

2. Allada, R.; Chung, B.Y. Circadian organization of behavior and physiology in Drosophila. Annu. Rev. Physiol. 2010, 72, 605-624. [CrossRef]

3. Malik, K.I.; Seth, R.K. Insect clocks: Implication in an effective pest management. Biol. Rhythm Res. 2017, 48, 777-788. [CrossRef]

4. Niepoth, N.; Ke, G.; de Roode, J.C.; Groot, A.T. Comparing behavior and clock gene expression between caterpillars, butterflies and moths. J. Biol. Rhythm. 2018, 33, 52-64. [CrossRef]

5. Linn, C.E.; Campbell, M.G.; Roelofs, W.L. Photoperiod cues and the modulatory action of octopamine and 5-hydroxytryptamine on locomotor and pheromone response in male gypsy moths, Lymantria dispar. Arch. Insect Biochem. Physiol. 1992, 20, 265-284. [CrossRef]

6. Minis, D.H.; Pittendrigh, C.S. Circadian oscillation controlling hatching: Its ontogeny during embryogenesis of a moth. Science 1968, 159, 534-536. [CrossRef] [PubMed]

7. Kobelkova, A.; Zavodska, R.; Sauman, I.; Bazalova, O.; Dolezel, D. Expression of clock genes period and timeless in the central nervous system of the Mediterranean flour moth, Ephestia kuehniella. J. Biol. Rhythm. 2015, 30, 104-116. [CrossRef]

8. Groot, A.T. Circadian rhythms of sexual activities in moths: A review. Front. Ecol. Evol. 2014, 2, 43. [CrossRef]

9. Bhattarai, U.R.; Li, F.; Katuwal Bhattarai, M.; Masoudi, A.; Wang, D. Phototransduction and circadian entrainment are the key pathways in the signaling mechanism for the baculovirus induced tree-top disease in the lepidopteran larvae. Sci. Rep. 2018, 8 , 17528. [CrossRef]

10. Dubowy, C.; Sehgal, A. Circadian rhythms and sleep in Drosophila melanogaster. Genetics 2017, 205, 1373-1397. [CrossRef] [PubMed]

11. Pfeiffenberger, C.; Lear, B.C.; Keegan, K.P.; Allada, R. Locomotor activity level monitoring using the Drosophila Activity Monitoring (DAM) System. Cold Spring Harb. Protoc. 2010, 2010, pdb prot5518. [CrossRef]

12. Yuan, Q.; Metterville, D.; Briscoe, A.D.; Reppert, S.M. Insect cryptochromes: Gene duplication and loss define diverse ways to construct insect circadian clocks. Mol. Biol. Evol. 2007, 24, 948-955. [CrossRef] [PubMed]

13. Beer, K.; Helfrich-Forster, C. Model and non-model insects in chronobiology. Front Behav. Neurosci. 2020, 14, 601676. [CrossRef] [PubMed]

14. You, M.; Ke, F.; You, S.; Wu, Z.; Liu, Q.; He, W.; Baxter, S.W.; Yuchi, Z.; Vasseur, L.; Gurr, G.M.; et al. Variation among 532 genomes unveils the origin and evolutionary history of a global insect herbivore. Nat. Commun. 2020, 11, 2321. [CrossRef]

15. Furlong, M.J.; Wright, D.J.; Dosdall, L.M. Diamondback moth ecology and management: Problems, progress, and prospects. Annu. Rev. Entomol. 2013, 58, 517-541. [CrossRef] [PubMed]

16. Rosato, E.; Kyriacou, C.P. Analysis of locomotor activity rhythms in Drosophila. Nat. Protoc. 2006, 1, 559-568. [CrossRef] [PubMed]

17. Levine, J.D.; Funes, P.; Dowse, H.B.; Hall, J.C. Signal analysis of behavioral and molecular cycles. BMC Neurosci. 2002, 3, 1. [CrossRef] 
18. Klarsfeld, A.; Leloup, J.C.; Rouyer, F. Circadian rhythms of locomotor activity in Drosophila. Behav. Process. 2003, 64, 161-175. [CrossRef]

19. Chiu, J.C.; Low, K.H.; Pike, D.H.; Yildirim, E.; Edery, I. Assaying locomotor activity to study circadian rhythms and sleep parameters in Drosophila. J. Vis. Exp. 2010, e2157. [CrossRef]

20. Giannoni-Guzman, M.A.; Avalos, A.; Marrero Perez, J.; Otero Loperena, E.J.; Kayim, M.; Medina, J.A.; Massey, S.E.; Kence, M.; Kence, A.; Giray, T.; et al. Measuring individual locomotor rhythms in honey bees, paper wasps and other similar-sized insects. J. Exp. Biol. 2014, 217, 1307-1315. [CrossRef]

21. Gentile, C.; Rivas, G.B.; Meireles-Filho, A.C.; Lima, J.B.; Peixoto, A.A. Circadian expression of clock genes in two mosquito disease vectors: Cry2 is different. J. Biol. Rhythm. 2009, 24, 444-451. [CrossRef] [PubMed]

22. Rund, S.S.; Lee, S.J.; Bush, B.R.; Duffield, G.E. Strain- and sex-specific differences in daily flight activity and the circadian clock of Anopheles gambiae mosquitoes. J. Insect Physiol. 2012, 58, 1609-1619. [CrossRef]

23. Pivnick, K.A.; Jarvis, B.J.; Gillott, C.; Slater, G.P.; Underhill, E.W. Daily patterns of reproductive activity and the influence of adult density and exposure to host plants on reproduction in the diamondback moth (Lepidoptera: Plutellidae). Environ. Entomol. 1990, 19, 587-593. [CrossRef]

24. Emery, P.; So, W.V.; Kaneko, M.; Hall, J.C.; Rosbash, M. CRY, a Drosophila clock and light-regulated cryptochrome, is a major contributor to circadian rhythm resetting and photosensitivity. Cell 1998, 95, 669-679. [CrossRef]

25. Lewis, T.; Taylor, L.R. Diurnal periodicity of flight by insects. Ecolo. Entomol. 1965, 116, 393-435. [CrossRef]

26. Miranda-Anaya, M.; Guevara-Fefer, P.; García-Rivera, B.E. Circadian locomotor activity in the larva and adult fall armyworm, Spodoptera frugiperda (Noctuidae): Effect of feeding with the resistant variety of maize CML67. Biol. Rhythm Res. 2014, 33, 475-486. [CrossRef]

27. Zavodska, R.; Fexova, S.; von Wowern, G.; Han, G.B.; Dolezel, D.; Sauman, I. Is the sex communication of two pyralid moths, Plodia interpunctella and Ephestia kuehniella, under circadian clock regulation? J. Biol. Rhythm. 2012, 27, 206-216. [CrossRef]

28. Glaser, F.T.; Stanewsky, R. Temperature synchronization of the Drosophila circadian clock. Curr. Biol. 2005, 15, 1352-1363. [CrossRef]

29. Bell-Pedersen, D.; Cassone, V.M.; Earnest, D.J.; Golden, S.S.; Hardin, P.E.; Thomas, T.L.; Zoran, M.J. Circadian rhythms from multiple oscillators: Lessons from diverse organisms. Nat. Rev. Genet. 2005, 6, 544-556. [CrossRef]

30. Roessingh, S.; Rosing, M.; Marunova, M.; Ogueta, M.; George, R.; Lamaze, A.; Stanewsky, R. Temperature synchronization of the Drosophila circadian clock protein PERIOD is controlled by the TRPA channel PYREXIA. Commun. Biol. 2019, 2, 246. [CrossRef]

31. Abhilash, L.; Kalliyil, A.; Sheeba, V. Responses of activity rhythms to temperature cues evolve in Drosophila populations selected for divergent timing of eclosion. J. Exp. Biol. 2020, 223. [CrossRef] [PubMed]

32. Guo, S.; Qin, Y. Effects of temperature and humidity on emergence dynamics of Plutella xylostella (Lepidoptera: Plutellidae). J. Econ. Entomol. 2010, 103, 2028-2033. [CrossRef]

33. Syrova, Z.; Sauman, I.; Giebultowicz, J.M. Effects of light and temperature on the circadian system controlling sperm release in moth Spodoptera littoralis. Chronobiol. Int. 2003, 20, 809-821. [CrossRef] [PubMed]

34. Carpenter, G.A.; Grossberg, S. A neural theory of circadian rhythms: Aschoff's rule in diurnal and nocturnal mammals. Am. J. Physiol. 1984, 247, R1067-R1082. [CrossRef] [PubMed]

35. Hooven, L.A.; Sherman, K.A.; Butcher, S.; Giebultowicz, J.M. Does the clock make the poison? Circadian variation in response to pesticides. PLoS ONE 2009, 4, e6469. [CrossRef]

36. Khalid, M.F.; Lee, C.Y.; Doggett, S.L.; Veera Singham, G. Circadian rhythms in insecticide susceptibility, metabolic enzyme activity, and gene expression in Cimex lectularius (Hemiptera: Cimicidae). PLoS ONE 2019, 14, e0218343. [CrossRef] 